\title{
Vision impairment in Liverpool: prevalence and morbidity
}

\author{
Michael Rogers
}

University of

Liverpool, Institute of Child Health, and Royal Liverpool Children's NHS Trust (Alder Hey)

M Rogers

Correspondence to: Dr Michael Rogers, Department of Community Child Health, Alder Hey Child Health, Alder Hey Road, Liverpool L12 2AP.

Accepted 22 December 1995

\begin{abstract}
A database related to the activities of the Liverpool vision assessment team was used to identify all children with vision impairment aged 0-16 years, resident in Liverpool, UK, on 1 April 1995. Prevalence rates were calculated for all children with vision impairment, and separately for two groups: those with uncomplicated vision impairment, and those with additional pathology. Visual tract pathologies were tabulated and compared. Associated handicapping conditions were defined and the extent of multiple disability was investigated for all vision impaired children, for very low birthweight children, and for those with cortical visual impairment. Of 199 children with vision impairment, 69 (35\%) had uncomplicated impairment and $130(65 \%)$ had additional and usually multiple pathology. There were 111 boys $(56 \%)$; the excess of males was not statistically significant. Prevalence rates per 10000 population were $18 \cdot 1$ for all vision impairment, $6 \cdot 3$ for uncomplicated vision impairment, and 11.8 for vision impairment complicated by additional pathology. Genetically determined disease accounted for over half the cases of uncomplicated vision impairment. Among the 130 children with additional pathology, cortical visual impairment was the commonest visual tract finding, affecting $64(49 \%) ; 86 \%$ had learning difficulties; $53 \%$ had cerebral palsy. Multidisability (two or more disabling conditions in addition to vision impairment) affected half the entire childhood vision impairment population. These data should assist health and education authorities to determine the size of the vision impairment problem and how it relates to other disabilities in childhood, and can facilitate resource allocation and service planning. (Arch Dis Child 1996; 74: 299-303)
\end{abstract}

Keywords: childhood visual impairment, prevalence, morbidity, multihandicap.

education (Liverpool City Council) and health (Liverpool Health Authority) are coterminous, and the community and hospital paediatric services are now integrated within the Royal Liverpool Children's NHS Trust. The team aims to see, or at least to have information about, every vision impaired child in Liverpool, and its concern with functional development and educational aspects of vision is complementary to hospital based ophthalmology and paediatrics.

The recent setting up of a database (on a Psion 3a 'palm-top' computer) relating to the team's activities has made it possible to study both the prevalence and morbidity associated with childhood vision impairment. The dataset for each child includes administrative details and basic clinical information derived from the team's assessments, supplemented by access to clinical records at Alder Hey Children's Hospital (particularly those of paediatric ophthalmology, paediatric neurology, the Child Development Centre and community child health) and to education records.

\section{Methods}

CASE DEFINITION

A child with vision impairment has corrected vision sufficiently abnormal to interfere with development or to have ongoing educational implications. In cases where distance acuity can be measured and is relevant (see discussion below), this equates with acuity of $6 / 18$ (Snellen) or worse in the better eye.

\section{CASE ASCERTAINMENT}

All visually impaired children known to the vision assessment team, resident in Liverpool on 1 April 1995, and aged 0-16 years were identified from the database by age, sex, and the absence or presence of pathology in addition to visual tract dysfunction. On this date there were a few cases of vision impairment not known to the team: these might have included very young children not yet referred, vision impairment of insidious onset in school age children, and those who had very recently moved into the city. Ascertainment was therefore a slight underestimate.

iverpool vision assessment team set up in 1976 to provide multidisciplinary assessment and support of children with vision impairment. The core members of the team are a senior educational psychologist, the senior advisory teacher of visually impaired children, and a consultant community paediatrician: this structure facilitates close links between health and education services. The geographical boundaries of
PREVALENCE

The total 0-16 year population in Liverpool was calculated from the Office of Population and Census Surveys (OPCS) mid-1993 population estimates, which were the most recent available. Prevalence rates in this study, and those 
quoted from elsewhere, are all per 10000 population.

VISUAL TRACT MORBIDITY

The clinical features of dysfunctional vision were tabulated separately for children with uncomplicated vision impairment and for those with additional pathology. Sex distribution was determined overall and among children with the most frequently occurring visual tract disorders.

\section{NON-VISUAL MORBIDITY}

Additional pathology was investigated in terms of six broad diagnostic categories - (1) cerebral palsy; (2) hydrocephalus; (3) hearing loss; (4) epilepsy; (5) learning difficulties; (6) other relevant conditions - using the database supplemented by medical and educational records. Cerebral palsy, hydrocephalus, and epilepsy were clinical diagnoses made by appropriate paediatric specialists. Hearing loss was defined as loss of $60 \mathrm{~dB}$ or more in the better ear, which is the local criterion for receiving specialist advisory support in school. Learning difficulties comprised (a) developmental delay in preschool children deemed likely to indicate later severe or moderate learning difficulties, (b) severe or moderate learning difficulties in older children as indicated in statements of special educational need. 'Other relevant conditions' covered causes of appreciable dysfunction (judged subjectively) not covered in the first five categories (see table 5). Emotional and behavioural problems were excluded from this classification because of difficulties with categorisation and assessment.

The number of categories of additional pathology was determined for each child, and tabulated for all children and for those of very low birthweight (VLBW, <1500 g) and with cortical visual impairment. The educational placements of children with and without additional non-visual pathology were also compared.

\section{Results}

One hundred and ninety nine visually impaired children were identified, of whom 111 (56\%) were boys: the male/female ratio was not statistically significant $(p=0 \cdot 14$, sign test). Sixty

Table 1 Causes of visual dysfunction in Liverpool children aged 0-16 years with uncomplicated vision impairment

\begin{tabular}{lcc}
\hline & Number & Per cent \\
\hline Albinism & 15 & 22 \\
Hereditary retinopathy & 13 & 19 \\
Congenital idiopathic nystagmus & 11 & 16 \\
Refractive error & 9 & 13 \\
Congenital cataract & 6 & 9 \\
Retinopathy of prematurity & 5 & 7 \\
Tumour & 2 & 3 \\
Microphthalmia +cataract & 2 & 3 \\
Optic atrophy & 2 & 3 \\
Various & 4 & 5 \\
Total & 69 & 100
\end{tabular}

${ }^{\star}$ One case each of optic nerve hypoplasia, optic neuritis, coloboma, keratitis. nine children $(35 \%)$ had uncomplicated vision impairment; the remaining $130(65 \%)$ had additional pathology.

\section{PREVALENCE}

The 0-16 years population of Liverpool was 110200 . Prevalence rates for visual impairment were 18.1 for all vision impaired children, 6.3 for those with uncomplicated vision impairment, and 11.8 for children with vision impairment and additional pathology.

VISUAL TRACT MORBIDITY

The causes of visual dysfunction in 69 children with uncomplicated vision impairment are shown in table 1 . All had a clear cut ophthalmological diagnosis accounting for visual impairment. Secondary manifestations (for example, non-idiopathic nystagmus, coincidental refractive error, and so on) have not been listed. Seven of the nine children with uncorrectable refractive error had high myopia. At least $39(56 \%)$ of this group had genetically determined disease (genetic data were not available for all relevant cases).

Findings related to visual dysfunction in the 130 children with vision impairment and additional pathology are shown in table 2. A few children had a straightforward diagnosis accounting for impaired vision, but this group was characterised by multiple vision related findings, the relative contributions of each of which to the resulting visual handicap were often unclear. Cortical visual impairment was the commonest single diagnosis, affecting 64 children (49\%). Nine of the 13 children with visual field defects had hemianopia associated with hemiplegic cerebral palsy.

\section{SEX DISTRIBUTION}

Table 3 shows distribution by sex for the most frequently identified causes of visual problems in the two groups. Nine out of 13 children with hereditary retinopathy, and 15 out of 27 with optic atrophy, were girls. Otherwise boys predominated, most notably in congenital idiopathic nystagmus (10 of 11).

Table 2 Findings related to visual dysfunction in Liverpool children aged 0-16 years with vision impairment and additional pathology: $n=130$

\begin{tabular}{lll}
\hline & Number & Per cent \\
\hline Cortical visual impairment & 64 & 49 \\
Nystagmus & 29 & 22 \\
Refractive error & 28 & 22 \\
Optic atrophy & 27 & 21 \\
Squint & 23 & 18 \\
Visual field defect & 13 & 10 \\
Retinopathy & 6 & 5 \\
Cataract & 6 & 5 \\
Amblyopia & 5 & 4 \\
Retinopathy of prematurity & 5 & 4 \\
Optic nerve hypoplasia & 4 & 3 \\
Tumour & 4 & 3 \\
Anophthalmia/microphthalmia & 3 & 2 \\
Ptosis & 3 & 2 \\
Coloboma & 2 & $1 \cdot 5$ \\
Various† & 4 & 3 \\
\hline
\end{tabular}

^ More than one finding applied to each child in many cases tOne case each of corneal opacity, albinism, glaucoma, gaze paresis. 
Table 3 Sex distribution of commonest causes of visual dysfunction, in Liverpool children with vision impairment aged 0-16 years. Values are numbers of cases

\begin{tabular}{lcc}
\hline & Male & Female \\
\hline Uncomplicated vision impairment & 8 & \\
Albinism & 4 & 7 \\
Hereditary retinopathy & 10 & 1 \\
Congenital idiopathic nystagmus & 5 & 4 \\
Refractive error & & \\
Vision impairment with additional pathology & 35 & 29 \\
Cortical visual impairment & 16 & 13 \\
Nystagmus & 18 & 10 \\
Refractive error & 12 & 15 \\
Optic atrophy & & \\
\hline
\end{tabular}

NON-VISUAL MORBIDITY

Table 4 shows the numbers of children with conditions falling into each of the six diagnostic categories of additional non-visual pathology. Multiple pathology was common (see table 6). Of the 112 children with learning difficulties $(56 \%$ of all children with vision impairment), 71 (63\%) had severe and 18 $(16 \%)$ moderate learning difficulties, and 23 children of pre-school age $(21 \%)$ had clinically ascertained developmental delay. Thirteen (54\%) of the 24 children with hydrocephalus had associated optic atrophy. Eleven children had educationally significant hearing loss. There were no cases of congenital rubella syndrome.

\section{MULTIPLE PATHOLOGY}

Table 6 shows how many of the six categories of additional non-visual pathology applied to each child. Ninety eight children ( $49 \%$ of all with vision impairment) suffered from at least two other disabling conditions. In 54 children vision impairment was combined with cerebral palsy and severe learning difficulties; 30 of these also had epilepsy.

Morbidity associated with very low birthweight There were 22 VLBW children $(11 \%$ of all children with vision impairment). Mean birthweight was $926 \mathrm{~g}$ (range 622-1460 g); mean gestation was 26.5 weeks (range 24-30 weeks). Relevant visual tract findings are shown in table 7.

Ten children ( $45 \%$ of the VLBW group) developed vision impairment as a result of retinopathy of prematurity (ROP), despite cryotherapy or laser photocoagulation in seven. Five had uncomplicated vision impairment which was severe in all (for example, requiring teaching by non-sighted methods).

Of the 12 children (55\%) whose vision impairment was not ROP related, seven

Table 4 Non-visual pathology associated with vision impairment in Liverpool children aged 0-16 years: numbers of children with conditions in the six diagnostic categories shown: $n=130$

\begin{tabular}{lcc}
\hline Diagnostic category & Number* & Per cent* \\
\hline Cerebral palsy & 69 & 53 \\
Hydrocephalus & 24 & 18 \\
Hearing loss & 11 & 8 \\
Epilepsy & 47 & 36 \\
Learning difficulties & 112 & 86 \\
Othert & 32 & 25
\end{tabular}

^Multiple pathology was common: see table 6 . †See table 5 .
Table 5 Non-visual pathology associated with vision impairment in Liverpool children aged 0-16 years: 'other' pathology not covered in its dysfunctional consequences by the remaining five diagnostic categories (see table 4) $n=32$. Values are numbers of cases

\begin{tabular}{lcc}
\hline Severe respiratory disease & & 6 \\
$\quad$ Asthma (frequent inpatient treatment) & 3 & \\
$\quad$ Bronchopulmonary dysplasia (severe) & 2 & \\
$\quad$ Repeated severe infections & 1 & \\
Cleft lip and palate & & 5 \\
Endocrine disorder & & 4 \\
$\quad$ Post-tumour & 3 & \\
$\quad$ Post-meningitis & 1 & \\
Severe feeding difficulties & & 3 \\
Gastrostomy & 2 & \\
$\quad$ Nasogastric feeding & 1 & \\
Scoliosis & & 3 \\
Meningomyelococle & & 2 \\
Facial abnormalities & & 2 \\
Limb abnormalities & & 2 \\
Paraplegia & & 2 \\
Tarious & & 8 \\
\hline
\end{tabular}

^One case each of: agenesis of corpus callosum, CHARGE association, congenital cardiac defect, Fanconi syndrome, Prader-Willi syndrome, neurofibromatosis, autism, hydrotic ectodermal dysplasia.

†Five children had multiple 'other' pathology.

developed ROP which regressed (following treatment in two). The remaining five children, all born before 1988, did not have eye examinations by an ophthalmologist until visual dysfunction became manifest; transitory ROP could therefore have been missed. All these 12 children had additional pathology.

Fourteen $(64 \%)$ of the VLBW group had ultrasound evidence of intraventricular haemorrhage (IVH). Eight had hydrocephalus (shunted in seven), of whom four developed optic atrophy. One child developed a large porencephalic cyst following IVH. The overall pattern of multiple disability in VLBW children is shown in table 6 . Five $(23 \%)$ had uncomplicated vision impairment, and 12 $(55 \%)$ had two or more additional disabilities.

\section{Morbidity associated with cortical visual impairment}

The distribution of additional pathology among the 64 children with cortical visual impairment is shown in table 6. This was a severely disabled group: none had uncomplicated vision impairment, and 34 (53\%) had three or more other pathologies. Sixty two (97\%) had established learning difficulties. Twenty six $(41 \%)$ had evidence of anterior

Table 6 Morbidity in Liverpool children aged 0-16 years with vision impairment (VI): showing numbers and percentages with no additional pathology (0) and with 1-5 additional disabling pathologies (see table 4): for all children with VI, very low birthweight (VLBW) children, and those with cortical visual impairment (CVI)

\begin{tabular}{|c|c|c|c|c|c|c|}
\hline \multirow{2}{*}{$\begin{array}{l}\text { No of } \\
\text { additional } \\
\text { pathologies }\end{array}$} & \multicolumn{2}{|c|}{$\begin{array}{l}\text { All children } \\
\text { with VI }\end{array}$} & \multicolumn{2}{|c|}{$\begin{array}{l}\text { VLBW children } \\
\text { with VI }\end{array}$} & \multicolumn{2}{|c|}{$\begin{array}{l}\text { Children } \\
\text { with CVI }\end{array}$} \\
\hline & No & $\%$ & No & $\%$ & No & $\%$ \\
\hline $\begin{array}{l}0 \\
1 \\
2 \\
3 \\
4 \\
5\end{array}$ & $\begin{array}{r}69 \\
32 \\
42 \\
42 \\
10 \\
4\end{array}$ & $\begin{array}{r}35 \\
16 \\
21 \\
21 \\
5 \\
2\end{array}$ & $\begin{array}{l}5 \\
5 \\
4 \\
7 \\
1 \\
0\end{array}$ & $\begin{array}{r}23 \\
23 \\
18 \\
32 \\
4 \\
0\end{array}$ & $\begin{array}{r}0 \\
7 \\
23 \\
25 \\
7 \\
2\end{array}$ & $\begin{array}{r}0 \\
11 \\
36 \\
39 \\
11 \\
3\end{array}$ \\
\hline Total & 199 & 100 & 22 & 100 & 64 & 100 \\
\hline
\end{tabular}


Table 7 Visual tract findings causing or contributing to vision impairment in very low birthweight children aged 0-16 years in Liverpool: $n=22$. Values are numbers of cases*

Retinopathy of prematurity

Myopia

Optic atrophy

Visual field defect (hemianopia)

Nystagmus

Cortical visual impairment

${ }^{\star}$ More than one finding applied to each child in some cases.

visual pathway disease in addition to cortical visual impairment.

\section{EDUCATIONAL PLACEMENT}

The education environment in Liverpool emphasises mainstream integration of children with vision impairment wherever possible. As table 8 shows, whereas $70 \%$ of children with uncomplicated vision impairment received mainstream education, only $13 \%$ of the children with additional pathology did so: in fact only two children of secondary school age with multiple disabilities were attending mainstream schools.

\section{Discussion}

It is usual ${ }^{4-6}$ and, on the face of it, straightforward to define vision impairment in terms of distance acuity, but there are drawbacks. In the first place, despite improved techniques such as preferential looking, Keeler cards, and Cardiff acuity cards, many children with vision impairment are too young or too disabled to cooperate sufficiently to obtain measurements. Thirty six per cent of children in this study were under five, $56 \%$ had learning difficulties, and $49 \%$ had two or more additional disabilities (these groups, of course, overlap considerably). In a West Sussex study of children with vision impairment $46 \%$ 'were unable to perform formal tests of visual acuity'. ${ }^{5} \mathrm{~A}$ case definition which cannot be applied to almost half a study population is at best of limited value.

Secondly, an emphasis on distance acuity diverts attention from other aspects of visual function such as near vision and accommodation, ${ }^{7}$ eye movements, visual fields, and contrast sensitivity. All of these, alone or in combination, may cause or contribute to a child's visual difficulties, especially at school.

Unless and until succinct quantifiable criteria emerge, which can be applied at all ages and across the spectrum of childhood disability, an overarching criterion of developmental and

Table 8 Educational placement of children with vision impairment (VI) aged 0-16 years in Liverpool: showing numbers and percentages under 5 (preschool), and in mainstream and special education.

\begin{tabular}{|c|c|c|c|c|}
\hline & \multicolumn{2}{|c|}{$\begin{array}{l}\text { Uncomplicated } \\
\text { VI }\end{array}$} & \multicolumn{2}{|c|}{$\begin{array}{l}\text { VI with additional } \\
\text { pathology }\end{array}$} \\
\hline & No & $\%$ & No & $\%$ \\
\hline $\begin{array}{l}\text { Preschool } \\
\text { Mainstream } \\
\text { Special }\end{array}$ & $\begin{array}{r}9 \\
48 \\
12\end{array}$ & $\begin{array}{l}13 \\
70 \\
17\end{array}$ & $\begin{array}{l}15 \\
17 \\
98\end{array}$ & $\begin{array}{l}12 \\
13 \\
75\end{array}$ \\
\hline Total & 69 & 100 & 130 & 100 \\
\hline
\end{tabular}

educational dysfunction, consistently applied with regular case review, remains the most reliable approach to case ascertainment.

Prevalence of vision impairment has probably been underestimated in the past. This is partly explained by the use of social security registration data ${ }^{589}$ : the criteria for registration do not cover all children with vision impairment, and some children who would qualify are not registered. Riise et $a l^{4}$ reported prevalence among Danish 0-15 year olds of $4 \cdot 1$, but although ascertainment was closely linked to registration (Hyvarinen L, personal communication), many children with educationally significant vision impairment would have been excluded by the case definition of $3 / 60$ or worse visual acuity in the better eye. In the West Sussex study, ${ }^{5}$ an overall prevalence rate of 6.5 suggests underreporting, unless impaired vision is less common in West Sussex than in Liverpool. The Royal National Institute for the Blind (RNIB) analysed returns from 33 local education authorities; the mean prevalence was 10.3 , with a range from $1 \cdot 8$ to $26 \cdot 2 .{ }^{10}$ OPCS, using census data and household sampling, suggested an overall rate of $20,{ }^{11}$ which is in line with this study.

Surveys which distinguish children with additional pathology have reported proportions varying between $33 \%$ and $50 \%$ in different Nordic countries, ${ }^{4} 61 \%$ in West Sussex, ${ }^{5}$ and $56 \%$ in the RNIB survey. ${ }^{10}$ OPCS estimated that $83 \%$ of children with a sight problem had an additional disability. ${ }^{11}$

The preponderance of boys probably reflects the increased vulnerability of boys to pathological insult. Otherwise, in terms of individual clinical conditions, numbers were too small for more detailed conclusions to be drawn, except that $\mathrm{X}$ linked inheritance of congenital idiopathic nystagmus presumably explained the 10:1 excess of boys with this condition. The sex ratio reached statistical significance in the national registers of Denmark and Finland, ${ }^{12}$ ascribed to a combination of $\mathrm{X}$ linked inheritance and undetermined prenatal and perinatal factors.

Comparison of the causes of vision impairment in different studies is complicated by differing methodologies and diverse patterns of aetiology in different parts of the world. ${ }^{13}$ Among Nordic children ${ }^{14}$ optic atrophy, ROP, cerebral amblyopia, and congenital cataract were identified as the most important causes. In a recent study of blind children in Chile, ${ }^{15}$ $30 \%$ had hereditary disease and $18 \%$ had vision impairment caused by ROP.

ROP continues to be a major cause of concern, ${ }^{13-17}$ but it accounted for less than half the cases of vision impairment associated with VLBW in Liverpool, and it is important to be clear that the issue is vision impairment caused by ROP, not the incidence or prevalence of ROP itself. The risk of ROP occurring is inversely related to birthweight and gestation, ${ }^{1316}$ and the survival of more very small babies is bound to mean that cases of ROP continue to occur. Spontaneous regression is common, however, and in selected cases 
treatment seems to be effective. ${ }^{1617}$ Vision impairment caused by ROP is not inevitable, and can be kept to a minimum by ophthalmological monitoring as an integral part of neonatal intensive care. ${ }^{16}$ It should never be assumed that a history of ROP accounts for any subsequent vision problems, which are at least as likely to be caused by sequelae of VLBW such as intraventricular haemorrhage. ${ }^{18}$ Myopia is also a well recognised complication of prematurity. ${ }^{19}$

The increasing prevalence of cortical visual impairment is probably both apparent, in the sense of increased professional awareness, and real because of the survival of more children with brain damage. Jan has commented that the study of cortical visual impairment 'is still in its infancy', ${ }^{20}$ although the functional implications for affected children are beginning to be addressed. ${ }^{21} 22$

Neither vision impairment itself nor most of the disabling conditions used to analyse coexistent non-visual pathology are precise clinical concepts, and each is associated with a spectrum of dysfunction ranging from borderline normality to severe disability. The survey of morbidity in this study is broad brush and descriptive, delineating and to some extent quantifying the concept of 'multidisabled visual impairment' (MDVI) which is already widely used in education. Comparison with further United Kingdom and European studies might show significant geographical variations in, for example, genetically determined eye disease. Well validated special needs registers, once these are achieved, could be used for this purpose. ${ }^{23}$ They could also address issues not covered by this study, for example the numbers and proportions of children with cerebral palsy, learning difficulties, hydrocephalus, and so on, who are also visually impaired. This would help to place vision impairment realistically in the broader context of childhood disability.

Assuming that Liverpool's experience is typical of the United Kingdom, what are the practical implications? Reliable prevalence rates and an overview of associated morbidity should be used to inform service planning, resource allocation, training, and working practices. As examples, commissioners and providers of health care can plan on the basis that about two per 1000 children have impaired vision, and the majority of these have complex disabilities: education authorities should provide specialist teacher support and equipment accordingly; community paediatricians need to acquire experience of vision impairment so that they can contribute; and cooperative and complementary working relations between ophthalmologists and paediatricians in this field are a necessity, not a desirable optional extra.

I wish to pay tribute to my colleagues on the Liverpool vision assessment team, Judy Poole and Christine Hirst. They continue to teach me a great deal and I am grateful for their advice and encouragement.

1 Hunt H, McKendrick O, Poole JJ, Pugh RE, Rosenbloom L, Turnock R. Visual impairment in childhood: 3 year experience of an assessment team in Liverpool. In: Smith $\mathrm{V}$, Kean J, eds. Visual handicap in children. London: Heinemann, Spastics International Medical Publications, 1979: 42-51.

2 Hill AE, McKendrick O, Poole JJ, Pugh RE, Rosenbloom $\mathrm{L}$, Turnock $\mathrm{R}$. The Liverpool visual assessment team: 10 years experience. Child Care Health Dev 1986; 12: 37-51.

3 Hirst C, Poole JJ, Snelling GS. Liverpool visual assessmen team 1985-1989: 5 years on. Child Care Health Dev 1993, 19: $185-95$.

4 Riise $R$, Flage $T$, Hansen $E$, et al. Visual impairment in Nordic children. I. Nordic registers and prevalence data. Acta Ophthalmol Copenh 1992; 70: 145-54.

5 Baird G, Moore AT. Epidemiology of childhood blindness. In: Fielder AR, Best AB, Bax MCO, eds. The management of visual impairment in childhood. Cambridge: Mac Keith Press, 1993: 1-8.

6 World Health Organisation. International classification of impairments, disabilities and handicaps. Geneva: WHO, 1980.

7 Hyvarinen L. Vision in children - normal and abnormal. Meaford, Ontario, Canada: The Canadian Deaf-Blind and Rubella Association, 1988.

8 Fine SR. Incidence of visual handicap in childhood. In: Smith V, Kean J, eds. Visual handicap in children. London: Heinemann, Spastics International Medical Publications, 1979: 36-41.

9 Peckham C. Vision in childhood. Br Med Bull 1986; 42 $150-4$.

10 Walker E, Tobin M, McKennell A. Blind and partially sighted children in Britain: the RNIB survey Vol.2. London HMSO, 1992.

11 Bone M, Meltzer H. OPCS surveys of disability in Great Britain, Report 3: The prevalence of disability among children. London: HMSO, 1989.

12 Riise R, Flage T, Hansen E, Rosenberg T, Rudanko SI Viggosson G. Visual impairment in Nordic children. IV. Sex distribution. Acta Ophthalmol Copenh 1992; 70 605-9.

13 Gilbert C. Prevention of childhood blindness. In: Fielder $\mathrm{AR}$, Best AB, Bax MCO, eds. The management of visual impairment in childhood. Cambridge: Mac Keith Press, 1993: 180-208.

14 Hansen E, Flage T, Rosenberg T, Rudanko SL, Viggosson G, Riise R. Visual impairment in Nordic children. III G, Riise R. Visual impairment in Nordic children. III. 15 Gilbert CE, Canovas R, Kocksch-de-Canovas R, Foster A Gilbert CE, Canovas R, Kocksch-de-Canovas R, Foster A.
Causes of blindness and severe visual impairment in children in Chile. Dev Med Child Neurol 1994; 36 326-33.

16 Royal College of Ophthalmologists and British Association of Perinatal Medicine. Retinopathy of prematurity: guidelines for screening and treatment. Report of a joint working party. London, 1995.

17 Flynn JT, Sola A, Good WV, Phibbs RH. Screening for retinopathy of prematurity - a problem solved? Pediatrics 1995; 95: 755-7.

18 Cooke RWI. Factors affecting survival and outcome at 3 years in extremely preterm infants. Arch Dis Child 1994, 71: F28-31.

19 Phelps DL. Retinopathy of prematurity. Pediatr Rev 1995 ; 16: $50-6$.

20 Jan JE Neurological causes and investigations. In: Fielder $\mathrm{AR}$, Best AB, Bax MCO, eds. The management of visual impairment in childhood. Cambridge: Mac Keith Press, 1993: 48-63.

21 Schenk-Rootbiet AJF, van Nieuwenhuizen O, Schiemanck $\mathbf{N}$, van der Graaf $\mathbf{Y}$, Willemse J. Impact of cerebral visual impairment on the everyday life of cerebral palsied children. Child Care Health Dev 1993; 19: 411-23.

22 Groenveld M, Jan JE, Leader P. Observations on the habilitation of children with cortical visual impairment. $\mathcal{f}$ Vis Impair Blindness 1990; 84: 11-5.

23 Johnson A. Use of registers in child health. Arch Dis Child 1995; 72: 474 